\section{Comparison amount of microphthalmia-associated transcription factor in vitiligo before and after narrowband- ultraviolet B therapy}

\section{Yulianto Listiawan, Linda Astari, Putri Hendria Wardhani \\ Department of Dermatology and Venereology, Faculty of Medicine, Airlangga University, Dr. Soetomo General Hospital, Surabaya, Indonesia}

\begin{abstract}
Vitiligo is the most commonly seen depigmentation disease with clinical manifestations of milk colored white macules, complex pathogenesis that is not well understood so that evolution of the disease is unpredictable and therapeutic outcomes are often unsatisfactory. Until now narrowband-ultraviolet B (NB-UVB) is considered the most effective and safe treatment for vitiligo. Therapy evaluation by looking at melanocytes function that can be seen with microphthalmia-associated transcription factor (MITF) immunohistochemistry will become more objective and accurate. This is a comparative analytic experimental study using pre-post test method comparing MITF in vitiligo patients before and after receiving NB-UVB conducted at Dr. Soetomo general hospital Surabaya, 12 vitiligo samples treated only with NB-UVB twice a week until 8 times therapies. The first exposure dose was 200 $\mathrm{mJ}$ and gradually increased $20 \%$ every therapy. Biopsy was performed before and after therapies and then MITF was compared. There was a significant difference between the amount of MITF in vitiligo before NB-UVB and after NB-UVB therapy stastistically, $\mathrm{p}=<0.001 \quad(\mathrm{p}=0.05)$. MITF is useful for indicators of treatment success.
\end{abstract}

\section{Introduction}

Vitiligo is the most commonly seen depigmentation disease with clinical manifestations of milk colored white macules. Vitiligo is an acquired disease with complex pathogenesis that is not well understood so that the evolution of the disease is unpredictable and the outcome of therapy is often unsatisfactory. This leads to a decrease in quality of life, anxiety, lack of confidence in establishing a relationship, and psychosocial stigma in vitiligo patients. ${ }^{1,2}$ Vitiligo accounts for $0.3-0.5 \%$ of the world's population. The prevalence of vitiligo has shown an increase over the past few decades..$^{1,3}$

Vitiligo is a multifactorial, polygenic disease, from many theories of disease pathogenesis, the most accepted is the interaction of genetic and nongenetic factors to affect the function and survival of melanocytes. ${ }^{1}$ The earliest formation of melanocytes is regulated by Microphthalmia-Associated Transcription Factor (MITF), a main gene for survival of melanocytes and key regulatory factors of melanogenic protein transcription. ${ }^{4}$ MITF is a new melanocytic marker that allows estimation of the number of melanocytes within the epidermis and to detect function deterioration, MITF is more accurate and the easiest to interpret because of clean core expression and minimal disturbance of pigments melanin cytoplasm, the best immunohistochemical marker for epidermal melanocytes. ${ }^{5-7}$ In Bastonini's study, 2015 reported a deficiency of MITF expression on the edge of vitiligo lesions that contribute to the change and loss of melanocytes. ${ }^{8}$

The principle of vitiligo therapy is to facilitate the repopulation of depigmented patches with active melanocytes that can migrate, and perform the biosynthesis of melanin. Until now Narrowband UVB (NBUVB) is considered to be the most effective and safe for vitiligo therapy. ${ }^{1}$ Clinicians evaluate the results of vitiligo therapy only with clinical repigmentation percentage..$^{1,4}$ Understanding of repigmentation until now is not even yet, only subjectively. The objective evaluation of repigmentation is important for clinicians as an indicator of success or failure of therapy. Evaluation of therapy by looking at the function and the amount of melanocytes will become more objective and accurate.

In this study will be evaluated the amount of MITF in vitiligo patient lesions prior to NB-UVB therapy compared with after NB-UVB therapy. By proving the role of MITF $\mathrm{n}$ by looking at increasing the number of MITF in vitiligo after NB-UVB therapy, it can be an indicator of the efficacy of vitiligo therapy.

\section{Materials and Methods}

A study was conducted on 24 samples consisting of 12 pre-test samples and 12 post-test samples. All samples meet sample
Correspondence: Putri Hendria Wardhani, Department of Dermatology and Venereology, Faculty of Medicine, Airlangga University, Dr. Soetomo General Hospital, Surabaya, Indonesia.

Tel: +62315501609

E-mail: putri_h_w@yahoo.com

Key words: MITF, NB-UVB, Vitiligo

Contributions: All the authors contributed equally.

Conflict of interest: the authors report no conflict of interest.

Received for publication: 1 February 2019. Accepted for publication: 11 February 2019.

This work is licensed under a Creative Commons Attribution-NonCommercial 4.0 International License (CC BY-NC 4.0).

(C) Copyright M.Y. Listiawan et al., 2019 Licensee PAGEPress, Italy

Dermatology Reports 2019; 11(s1):8030 doi:10.4081/dr.2019.8030

requirements and are willing to participate in the research by signing information for consent, informed consent and medical action approval sheets. The research was conducted from May 2017 until August 2017 at Outpatient Clinic, Dr. Soetomo general hospital Surabaya. Each sample was recorded and $3 \mathrm{~mm}$ biopsy biopsy was performed, and MITF immunohistochemistry were performed to calculate the amount of MITF in two fields of view, one view per millimeter.

\section{Results}

We did the normality test to know the distribution of data in this study. This study used the Shapiro-Wilk parameter because the total number of patients was less than 50. From the Shapiro-Wilk parameter, the difference in the amount of MITF in vitiligo before and after NB therapy -UVB was normally distributed distribution $(p=0,024)$, $(\mathrm{p}>0.05)$. Normally distributed variables use paired $t$ test (Table 1).

With paired t test, $\mathrm{p}$ value $=0.000$ $(p=<0.05)$. In interpreting the data, the $p$ value is reported as $p=<0.001$ to prevent multiple interpretations because the $\mathrm{p}$ value $=0.000$ does not mean pure zero value. Statistically, it was found that there was a significant difference between the amount of MITF in vitiligo before NB-UVB and vitiligo therapy after NB-UVB therapy as 


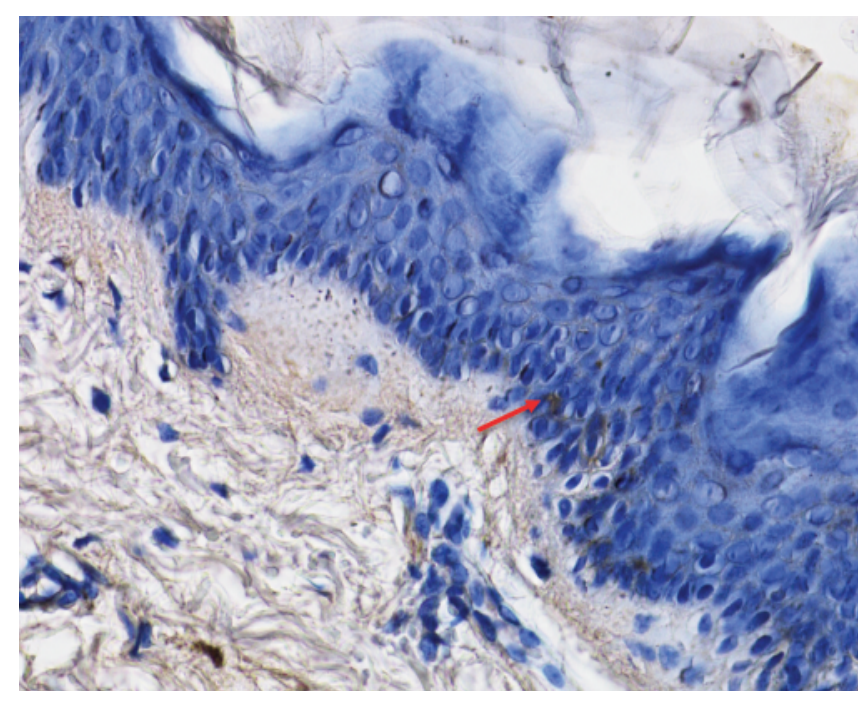

Figure 1. MITF before NB-UVB therapy.

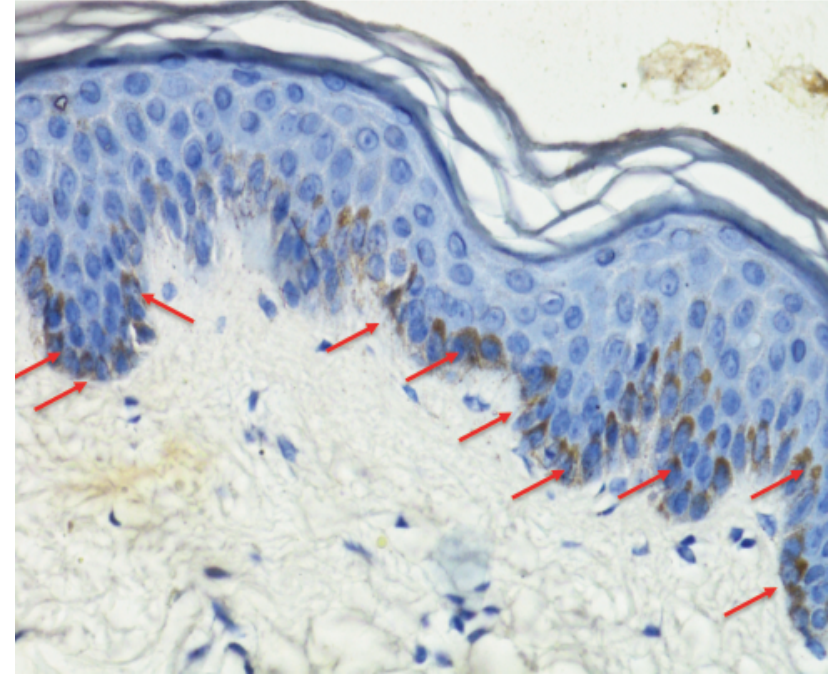

Figure 2. MITF after NB-UVB therapy.

Table 1. Normality Test.

\begin{tabular}{|c|c|c|c|}
\hline & \multicolumn{3}{|c|}{ Shapiro-Wilk } \\
\hline & Statistic & df & Sig. \\
\hline $\begin{array}{l}\text { Difference in the amount of MITF in vitiligo } \\
\text { before and after NB therapy -UVB }\end{array}$ & .948 & 12 & .612 \\
\hline
\end{tabular}

Table 2. Paired t test.

\begin{tabular}{lcccc} 
& Mean (s.d) & Difference (s.d) & CI95\% & p \\
$\begin{array}{lccc}\text { The amount of MITF in vitiligo prior } \\
\text { to NB-UVB therapy }(\mathrm{n}=12)\end{array}$ & $2,5(2,28)$ & $7,92(4,44)$ & $5,09-10,74$ & $<0,001$ \\
$\begin{array}{l}\text { The amount of MITF in vitiligo } \\
\text { after NB-UVB therapy }(\mathrm{n}=12)\end{array}$ & $10,42(3,63)$ & & \\
\hline
\end{tabular}

measured by MITF painting in 2 field of view, $\mathrm{p}=<0.001(\mathrm{p}=0.05)$ (Table 2$)$.

\section{Discussion}

In vitiligo before the treatment of NBUVB (Figure 1) obtained at most four melanocyte cells per one millimeter field of view and not rarely found no melanocyte in one field of view. In the two most visible fields found eight melanocytes, and two patients had no melanocytes at all. In vitiligo after NB-UVB therapy (Figure 2) there were at most sixteen melanocytes in two field of view and at least five melanocytes. In one field of vision there were found to be nine melanocytes, and at least two melanocytes in one field.

Statistically, it was found that there was a significant difference between the amount of MITF in vitiligo before and after NBUVB therapy as measured by MITF paint- ing in 2 field of view, $p=<0.001 \quad(p=0.05)$. This proves that MITF can be used to monitor the evaluation of vitiligo therapy.

Vitiligo is a depigmentation disorder characterized by loss of melanocyte function in the epidermal, multifactorial and pathogenic causes that overlap one another. Many studies have proven that morphological and functional melanocyte abnormalities exist. Previous research has proposed a mechanism involving MITF, a transcriptional factor that controls the melanin synthesis pathway. UV can induce the activation of transcription factors, one of which is important is MITF, a gene that acts to synthesize melanin found in melanosomes and is exported to keratinocytes. ${ }^{9,10}$ This is in line with the results of this study that an increase in the amount of MITF after NBUVB therapy was compared before NBUVB therapy, so it can be concluded MITF has a role as an objective evaluation of vitiligo therapy.

\section{Conclusions}

Increasing number of MITF in vitiligo patients after receiving NB-UVB therapy than before NB-UVB therapy is statistically different significantly. This suggests MITF has a role as an indicator of the success of vitiligo therapy.

\section{References}

1. Birlea SA, Spritz RA, Norris DA. Vitiligo. Dalam: Wolff K, Goldsmith LA, Katz SI, Gilchrest BA, Leffel DJ, editors. Fitzpatrick's Dermatology General Medicine. 8th Ed. New York: McGraw Hill Co; 2013. pp 792-803.

2. Kutlubay Z, Karakus O, Engin B, Serdaroglu S. Vitiligo as autoimun disease. J Turk Acad Dermatol 2012;6: 126r1.

3. Alikhan MD, Felsten LM, Daly M, Petronic-Rosic V. Vitiligo: A comprehensive overview. J Am Acad Dermatol 2011;65:473-91.

4. Park HY, Yaar M. Biology of melanocytes. Dalam: Wolff K, Goldsmith LA, Katz SI, Gilchrest BA, Leffel DJ, editors. Fitzpatrick's Dermatology in General Medicine 8th Ed. New York: McGraw Hill Co; 2013. pp 792-803.

5. Prieto VG, Shea CR. Immunohistochemistry of melanocytic proliferations. Arch Pathol Lab Med 2011;135:853-9.

6. Sheffield MV, Yee H, Dorvault CC, et al. Comparison of Five Antibodies as 
markers in the diagnosis of melanoma in cytologic preparations. Am J Clin Pathol 2002;118:930-6.

7. Nybakken GE, Sargen M, Abraham R, et al. MITF acurately highlight epidermal melanocytes in atypical intraepidermal melanocytic proliferations. Am J Dermatopathol 2013;35(1):25-9.
8. Bastonini E, Kovacs D, Picardo M Skin pigmentation and pigmentary disorders: focus on epidermal/ dermal cross-talk. Ann Dermatol 2016;28:27989.

9. Lee $\mathrm{CH}$, Wu SB, Hong $\mathrm{CH}$, Yu HS, Wei YH. Molecular mechanisms of UVinduced apoptosis and its effects on skin residential cells: the implication in UVbased phototherapy. Int $\mathrm{J}$ Mol Sci 2013;14:6414-35.

10. Videira IFS, Magina S, Moura DFL. Mechanisms regulating melanogenesis. An Bras Dermatol 2013;88:76-83. 